\title{
A AMEAÇA “FANTASMA” DA PRIVATIZAÇÃO À EDUCAÇÃO BÁSICA PÚBLICA NA AMAZÔNIA PARAENSE ${ }^{1}$
}

\author{
Fabrício Aarão Freire Carvalho \\ Andréa Barbosa Gouveia
}

\section{Resumo}

A pesquisa bibliográfica e documental teve por objetivo analisar o papel do Estado, a partir da lógica de financiamento proposta pelas novas regulamentações voltadas para a educação básica e seu efeito indutor no processo de mercantilização / privatização da educação pública paraense, no período de 2013 a 2018. Trata-se de pesquisa qualitativa sobre o arcabouço legal, voltado para a regulamentação da educação básica da Amazônia paraense, privilegiando os dados educacionais de oferta da educação básica e da execução orçamentária do Estado. A análise dos dados revelou tendências de encolhimento do setor público e de avanços do setor privado na oferta da educação básica, no acesso ao fundo público. O Estado desempenhou um papel importante viabilizando um conjunto de medidas legais que intensifica a lógica da racionalidade financeira para a educação, permitindo avanço "silencioso" do processo de privatização da educação básica, destinação de recursos financeiros públicos para a iniciativa privada e estabelecimento das parcerias públicoprivadas no estado.

Palavras chave: política educacional; educação básica; financiamento; mercantilização / privatização.

\section{THE PHANTON MENACE FROM PRIVATIZATION TO BASIC EDUCATION AT AMAZONIA PARAENSE}

\begin{abstract}
The bibliographic and documentary research aimed to analyze the role of the State from the logic of financing proposed by the new regulations aimed at Basic Education and its inducing effect in the process of mercartilization/privatization of public education in Pará from 2013 to 2018. A qualitative research about legal norms sustains the basic education regulation in Amazonia paraense, highlighting educational access data and data from State budget execution. The analysis of the data revealed trends of shrinkage in the public sector and advances in the private sector in the provision of basic education in accessing the public fund. The State played an important role in enabling a set of legal measures that intensified the logic of financial rationality for education, which has allowed the "silent" advance of the privatization process of basic education, the allocation of public financial resources for private initiative and establishment of publicprivate partnerships in the state.
\end{abstract}

Keywords: education policies; basic education; financing; mercantilization / privatization.

\section{LA AMENAZA "FANTASMA" DE LA PRIVATIZACIÓN A LA EDUCACIÓN BÁSICA PÚBLICA EN LA AMAZONÍA PARAENSE}

\section{Resumen}

La investigación bibliográfica y documental tuvo como objetivo analizar el papel del Estado, basado en la lógica de financiamiento propuesta por las nuevas regulaciones dirigidas a la Educación Básica y su efecto inductor en el proceso de mercantilización/ privatización de la educación pública en Pará de 2013 a 2018. Esta es una investigación cualitativa del marco legal dirigido a la regulación de la educación básica en la

\footnotetext{
1 A pesquisa é resultado de Atividade de Estágio Pós-Doutoral realizado na UFPR em 2019, financiada pela Coordenação de Aperfeiçoamento de Pessoal de Nível Superior (CAPES) - Edital n. 21/2018 - PROCAD Amazônia.
} 
región amazónica de Pará, privilegiando los datos educativos sobre la provisión de educación básica y la ejecución presupuestaria del Estado. El análisis de los datos reveló tendencias de contracción en el sector público y avances en el sector privado en la provisión de educación básica para acceder al fondo público. El Estado desempeñó un papel importante al permitir un conjunto de medidas legales que intensifica la lógica de la racionalidad financiera para la educación, permitiendo un avance "silencioso" en el proceso de privatización de la educación básica, la asignación de recursos financieros públicos para la iniciativa privada y el establecimiento de asociaciones públicas-privado en el estado.

Palabras clave: política educativa; educación básica; financiación; mercantilización / privatización.

\section{INTRODUÇÃO}

Estudos recentes (SANTOS, 2014; SALVADOR, 2017; PERONI e SHEIBE, 2017; GARCIA, 2018; ADRIÃO, 2018) demonstram que a educação básica vem sendo assombrada pelo "fantasma" da mercantilização / privatização. Em que pesem as orientações legais e as tensões entre o Estado e o mercado nessa direção - estimular o processo de mercantilização / privatização — já datarem desde há muito tempo em âmbito internacional (SALVADOR, 2017) e, no Brasil, terem se intensificado a partir da década de 1990, este processo, dependendo do cenário político econômico e do processo de correlação de forças entre o público e o privado em âmbito nacional e nos diferentes estados da federação, manifesta-se de forma diferenciada, tanto em ritmo quanto em intensidade, nos sistemas de ensino da federação brasileira. Ainda que as normativas legais tenham validade para todo o Brasil, há adequação dos processos por parte dos governos subnacionais, distinções na atuação do setor privado, nas políticas e programas e nos impactos nas redes de ensino e nas escolas (ADRIÃO, 2018). Compreender e produzir evidências empíricas de como o processo de mercantilização / privatização da educação vem se dando no país, em cada ente federado, pode se converter em uma importante ferramenta de combate aos seus avanços.

O presente artigo sistematiza informações acerca de como este processo vem se desenvolvendo no estado do Pará, um dos importantes estados da Amazônia brasileira. Encontrase organizado em seções, além desta introdução. A primeira apresenta um breve contexto acerca da importância do objeto e apresenta aspectos metodológicos da pesquisa realizada; a segunda apresenta informações de revisão bibliográfica acerca do tema investigado; a terceira seção apresenta uma análise da base legal de estímulo ao processo de privatização; a quarta apresenta os resultados do estudo e os avanços do processo de privatização da educação básica no contexto paraense/amazônico. Finalmente, apresenta as considerações finais e avanços do estudo para o tema investigado.

\section{DO OBJETO, QUESTÃO DE INVESTIGAÇÃO, OBJETIVOS E ASPECTOS METODOLÓGICOS}

Esta pesquisa tem como objeto de estudo o processo de privatização da educação básica no Pará, estado pertencente à Amazônia legal brasileira. O período analisado foi de 2013 a 2018, quando centraremos a análise deste processo, levando em conta apenas a dimensão da privatização da oferta educacional, a partir da análise das normativas legais aprovadas por este ente subnacional e dos dados de matrícula, número de estabelecimentos por dependência administrativa e informações de financiamento público do setor privado.

Segundo Peroni e Sheibe (2017), o processo de privatização acontece de várias formas ocorre tanto por meio da oferta direta de serviços educacionais por instituições privadas, como também por meio de políticas em que o privado disputa o fundo público e o conteúdo das políticas públicas educacionais. Faz-se necessário compreender, mais especificamente, qual o papel do 
Estado e a lógica de financiamento proposta pelas novas regulamentações voltadas à educação básica e seu efeito determinante / indutor do processo de mercantilização e privatização da educação pública paraense - via acesso ao fundo público e ampliação da oferta pela rede privada.

Visando responder à questão apresentada, este estudo lança-se ao desafio de analisar o papel do Estado, a lógica de financiamento proposta pelas novas regulamentações voltadas para a educação básica e o seu efeito determinante / indutor no processo de mercantilização / privatização da educação pública paraense no período de 2013 a 2018. Para tanto, faz-se necessário: mapear os dispositivos legais nacionais e paraense voltados à educação básica em que, nos textos, seja apresentada indicação de parceria público / privado ou estímulos de acesso pelo setor privado ao fundo público; analisar os dados de oferta - matrícula e estabelecimentos de ensino - da educação básica, por dependência de ensino, com o foco voltado para a descrição do comportamento e tendências da rede pública e privada; investigar os gastos com a educação por função e subfunção e identificar as transferências de recursos do orçamento do estado para as entidades privadas.

A pesquisa foi realizada em duas etapas, quais sejam: a etapa de base bibliográfica, que permitiu estabelecer um diálogo com a literatura mais recente produzida sobre o tema da mercantilização / privatização da educação básica no Brasil (SANTOS, 2014; SALVADOR, 2017; PERONI e SHEIBE, 2017; GARCIA, 2018; ADRIÃO, 2018; e a etapa de base documental que esteve consubstanciada em documentos legais que definem elementos / estímulos para o processo de parceria público / privado na educação básica: Lei n. 8.897/1995; Lei n. 9.074/1995; Emenda Constitucional (EC) n. 19/1998; Lei n. 9.637/1998; a Lei n. 9.648/1998; a Lei n. 9.790/1999; Lei Complementar n. 101/2000; Lei n. 11.079/2004; Decreto federal n. 5.977/2006; Lei n. 12.101/2009; Lei n. 13.019/2014; Lei n. 13.204/2015; EC n. 95/2016; Lei n. 13.415/2017; Lei n. 13.429/2017; Lei n. 13.467/2017.

$\mathrm{Na}$ intenção de atingir os objetivos especificados, adotou-se o paradigma de pesquisa qualitativa, o que permitiu fazer uma investigação do fenômeno na dinâmica histórica em que o mesmo se manifesta. Para tal análise, a opção foi organizar e articular informações quantitativas (GAMBOA, 1995; OLIVEIRA, 2008) dos indicadores de acesso - dados de matrícula e estabelecimentos de ensino da rede pública e privada - e de financiamento da educação do estado durante o período de 2013 a 2018. Conforme sugerido por Fagnani (2007) e, considerando que quantidade e qualidade são elementos intrínsecos a quase todos os objetos e fenômenos educativos, para a análise dos dados financeiros da educação no estado do Pará, bem como das transferências de recursos para as entidades privadas do orçamento do estado, esta pesquisa considerou dois aspectos importantes: o destino dos recursos e a grandeza (montante) dos mesmos. A análise do primeiro permitiu identificar onde e em que, especificamente, foram gastos os recursos da educação. Quanto à grandeza (montante) ou magnitude dos gastos, permitiu esclarecer qual a situação dos gastos em educação e das transferências para o setor privado, em relação aos gastos do estado durante o período de 2013 a 2018. Para a análise dos dados financeiros no período de 2013 a 2018, estes dados foram corrigidos em relação à inflação. Para tanto, aplicou-se o deflator IPCA (Índice de Preços ao Consumidor Amplo) do Instituto Brasileiro de Geografia e Estatística (IBGE), mesmo deflator proposto pela EC n. 95/2016, para corrigir os gastos do governo federal com educação por um período de 20 anos. O índice utilizado ano a ano foi calculado por meio de instrumento online denominado "Calculadora do cidadão" disponível no site do Banco Central.

As fontes de dados foram o Instituto Nacional de Estudos e Pesquisas em Educação (INEP - Censo Escolar), e a interface de dados do Laboratório de Dados Educacionais da Universidade Federal do Paraná / Universidade Federal de Goiás (UFPR/UFG) e o Sistema de Informações sobre Orçamentos Públicos em Educação (SIOPE). 


\section{DA REVISÃO DA LITERATURA ACERCA DO PROCESSO DE MERCANTILIZAÇÃO / PRIVATIZAÇÃO DA EDUCAÇÃO BÁSICA}

Conforme evidenciado por estudos recentes (SANTOS, 2014; SALVADOR, 2017; PERONI e SHEIBE, 2017; GARCIA, 2018; ADRIÃO, 2018) a educação básica - além do ensino superior - vem sendo fortemente assombrada pelo "fantasma" da mercantilização e privatização, tanto na estrutura da oferta quanto na organização da gestão - currículo, fornecimento de materiais - no âmbito dos diferentes sistemas de ensino. A diferenciação entre mercantilização compreendida como " [...] transformação, no âmbito do capitalismo, de bens materiais e simbólicos em mercadoria. $\mathrm{Na}$ área da educação, consiste na transformação desse direito em um bem ou serviço que pode ser vendido / comprado segundo a lógica do mercado privado" (SALVADOR, 2017) - e privatização é importante neste contexto. Se mercantilização é este processo mais amplo de conversão de todos os bens sociais em mercadoria, a privatização, nos termos de Rikowski (2017, p. 399-400) pode assumir duas formas básicas: a "privatização clássica" ou "privatização direta", que envolve a venda de ativos públicos diretamente para uma empresa, grupos de investidores e investidores individuais; e, a segunda forma de privatização, em que há a tomada de controle sobre a educação por parte das empresas / setor privado sem a transferência de propriedades dos ativos do setor público.

A história da educação brasileira sempre esteve permeada pela relação entre o público e o privado (VIZZOTTO, CORCETTI, PIEROZAN, 2017; SALVADOR, 2017). Contudo, foi depois da aprovação da Constituição Federal (CF 1988), e a partir da reforma de meados dos anos 1990, com a implementação do Plano Diretor de Reforma do Aparelho do Estado (PDRAE), que o discurso oficial e a necessidade da incorporação dos princípios de gerência privada no espaço público, bem como as parcerias público-privadas na educação foram se intensificando (SANTOS, 2014).

A partir de então, durante os governos presidenciais de Fernando Henrique Cardoso (FHC, do PSDB - 1995 a 2002), foram criadas e aprovadas sete medidas legais que legitimaram a interlocução do poder público com o setor privado e permitiram o acesso ao fundo público pelos grupos econômicos da educação privada: a Lei n. 8.897/1995 que dispõe sobre o regime de concessão e permissão da prestação de serviços públicos previsto no Art. 175 da CF; a Lei n. 9.074/1995 que estabeleceu normas para outorga e prorrogações das concessões e permissões de serviços públicos; a Emenda Constitucional (EC) n. 19/1998 que legalizou a relação entre os setores público e privado; a Lei n. 9.637/1998 que dispõe sobre a qualificação de entidades como organizações sociais; a criação do Programa Nacional de Publicização, a extinção dos órgãos e entidades que menciona e a absorção de suas atividades por organizações sociais; a Lei n. 9.648/1998 que alterou a Lei de Licitações e Contratos; a Lei n. 9.790/1999 que dispõe sobre a qualificação de pessoas jurídicas de direito privado, sem fins lucrativos, como Organizações da Sociedade Civil de Interesse Público (Oscip), bem como institui e disciplina o termo "parceria"; a Lei Complementar n. 101/2000 que regulamentou a EC n. 19/1998 e estabeleceu normas de finanças públicas voltadas para a responsabilidade na gestão fiscal.

Esse processo de construção das formas de regulação jurídica da parceria entre o setor público e o privado teve continuidade durante os governos Lula (2003 a 2011 - com a aprovação de três medidas legais) e os governos Dilma (2011 a 2016 - com a aprovação de duas medidas legais), sendo fortemente intensificado e estimulado durante o governo Temer (2016 a 2018) com a aprovação de quatro medidas legais que contribuem para o agravamento das tendências de

\footnotetext{
${ }^{2}$ Metáfora utilizada com o sentido de evidenciar que o processo de privatização da educação básica ainda caminha nas sombras e de forma lenta, gradual e quase imperceptível - para grande parte da sociedade; como um "fantasma" vem se expandindo e tendo cada vez mais acesso ao fundo público.
} 
mercantilização e privatização da educação no Brasil, tornando o Estado cada vez "menor" para as políticas sociais e "máximo" para o capital.

Preocupado com o avanço crescente das políticas de mercantilização e privatização da educação básica no Brasil e no mundo, a Internacional da Educação (IE), entidade à qual a Confederação Nacional dos Trabalhadores em Educação (CNTE) é filiada, organizou um levantamento mundial acerca do assunto incluindo o Brasil. No país, a pesquisa foi coordenada por Evilásio Salvador e realizada em parceria com uma equipe de pesquisadores da Universidade de Brasília (UnB).

A pesquisa teve por objetivo: analisar o número de matrículas e estabelecimentos da educação pública e privada no período de 2009 a 2013; investigar os orçamentos públicos federal e estaduais e dos componentes de privatização dos gastos orçamentários em educação, identificando e mensurando formas de financiamento direto e indireto da educação privada no país. Em síntese, o estudo revelou que "[...] as matrículas na educação básica apresentaram tendência de queda no período considerado. No período de 2009 a 2013, houve queda de 4,8\% em matrículas, passando de 52,5 milhões de estudantes para 50 milhões" (SALVADOR, 2017, p. 17). Contudo, quando considerados os dados por dependência administrativa pública e privada, enquanto a matrícula pública teve redução de $8,5 \%$ (-3.838.294) a rede privada cresceu 17,8\% (1.300.290). O detalhamento desses dados, no período analisado, revelou crescimento apenas da rede federal $(33,6 \%)$ e da rede privada $(17,8 \%)$ no atendimento à educação básica; e queda nas redes estadual (queda de 2,8 milhões de matrículas) e municipal (queda de 1,1 milhão) de ensino (SALVADOR, 2017, p. 18). No que se refere ao número de estabelecimentos públicos e privados, enquanto a rede estadual registrou redução de 1.546 estabelecimentos $(-4,7 \%)$, a rede municipal fechou outros 8.565 estabelecimentos (-6,6\%); a federal apresentou crescimento de 212 estabelecimentos e a privada de 3.137 novos estabelecimentos de educação $(+8,8 \%)$ (SALVADOR, 2017, p. 39). confirmam

De acordo com a pesquisa, os dados de matrícula e estabelecimentos coletados e analisados

[...] tendência de avanços da mercantilização e privatização na educação básica do país. Fenômeno silencioso, encoberto pela forte expansão da matrícula privada no ensino superior, mas também extremamente comprometedor do direito à educação e da educação pública como bem público inalienável (SALVADOR, 2017, p. 72).

A mesma tendência também foi observada no que se refere à transferência de recursos orçamentários diretos para o setor privado, mais especificamente as transferências realizadas para instituições privadas sem fins lucrativos:

[...] as transferências para o setor privado educacional evoluíram de $\mathrm{R} \$ 1.212 .976 .675,32$ (2010) para $\mathrm{R} \$ 1.606 .075 .932,61$ (2014), isto é, um crescimento real de $32,41 \%$, acima da inflação e com comportamento superior aos gastos totais com educação dessas UFs, que cresceram 12,08\% [...]. Isso é uma clara indicação que vem aumentando, do ponto vista orçamentário, a transferência de recursos públicos para o setor privado em um ritmo maior $(2,68$ vezes) que o crescimento dos gastos diretos do governo nas despesas correntes, provavelmente de custeio (SALVADOR, 2017, p. 105).

Adrião (2018), em estudo recente acerca da privatização da educação básica no Brasil, realizado a partir de mapeamento das produções nacionais e internacionais, destacou três dimensões sob as quais podemos perceber os efeitos do processo de privatização da educação básica: na oferta educacional; na gestão da educação; e no currículo, quando os argumentos da 
autora revelam a complexidade do processo. Neste estudo centraremos a análise no processo paraense, levando em conta apenas a dimensão da privatização da oferta educacional, a partir da análise das normativas legais aprovadas por este ente subnacional; dos dados de matrícula e número de estabelecimentos por dependência administrativa; e das informações de financiamento público direto ao setor privado.

\section{DO LEVANTAMENTO DA BASE LEGAL PARAENSE QUE ESTIMULA O PROCESSO DE MERCANTILIZAÇÃO / PRIVATIZAÇÃO}

Conforme já sinalizado neste artigo, a partir de meados da década de 1990, durante o governo FHC, foram criadas e aprovadas medidas legais que legitimaram a interlocução do poder público com o setor privado e permitiram o acesso ao fundo público pelos grupos econômicos da educação privada. O processo de reforma do Estado implementado a partir de então permitiu uma série de medidas, como a flexibilização e estímulo à entrada de capital estrangeiro, corte de gastos públicos e abertura comercial. O período de governos progressistas na coalização encabeçada pelo Partido dos Trabalhadores, ainda que não tenha interrompido o processo, diminuiu o ritmo e a intensidade, podendo-se observar "[...] uma tendência de fortalecimento do estado", mesmo sem "[...] impor limites à privatização por meio de dispositivos legais e acabou consagrando o repasse de recursos públicos às instituições privadas" (SALVADOR, 2017, p. 73).

Após a posse de Michel Temer na Presidência da República em 2016, em decorrência de um golpe de Estado, retoma-se o ritmo intenso e aprova-se um conjunto de iniciativas que caminham no sentido de estimular a relação público-privada e cortar direitos dos trabalhadores brasileiros. Segundo Salvador (2017, p. 82):

[...] Os cenários que se apresentam no horizonte, a partir da posse de Temer, é de um agravamento das tendências de mercantilização e privatização da educação no Brasil [...] A Emenda Constitucional n 95/2016 inviabiliza a vinculação dos recursos a políticas sociais nos moldes desenhados pela Constituição, ao congelar por 20 anos as chamadas despesas primárias do governo. De fato, a forte redução dos gastos correntes determinados pela Emenda não apenas fragiliza sobremaneira as políticas sociais como compromete a própria capacidade do Estado de implementar programas e ações em prol do desenvolvimento. Por outro lado, não foi fixado limite algum para despesas com o pagamento de juros da dívida pública, o que demonstra de forma inequívoca a opção em privilegiar o capital em detrimento da classe trabalhadora.

Foi uma medida que, em síntese, estimula a subordinação formal e concreta do setor educacional ao setor privado, com fins de lucro. Empreende todo um esforço no sentido de naturalizar ${ }^{3}$ as regras de mercado para o setor da educação e, neste sentido, o Estado capitalista vem cumprindo um papel importante.

No estado do Pará, ao longo do período de 2004 a 2018, sob os três mandatos de Simão Jatene (PSDB - 2003 a 2006; 2011 a 2014 e 2015 a 2018), foram criadas e aprovadas medidas legais que legitimaram a interlocução do poder público com o setor privado, conforme pode ser observado na Tabela 1 , a seguir:

\footnotetext{
3 O mercado não é natural, logo a transformação do direito à educação em mercadoria também não o é (POLANYI, 2000). As relações de mercado precisaram do Estado para se estabelecer e hoje a transformação do direito à educação em mercadoria vem contando com o apoio decisivo do Estado.
} 
Tabela 1: Base legal que estimula o processo de mercantilização / privatização - Pará - 2004 a 2018

\begin{tabular}{|c|c|c|}
\hline $\begin{array}{l}\text { GOVERNO, } \\
\text { PARTIDO }\end{array}$ & LEGISLAÇÃO & $\begin{array}{c}\text { EFEITO INDUTOR } \\
\text { MERCANTILIZAÇÃO/PRIVATIZAÇÃO }\end{array}$ \\
\hline $\begin{array}{l}\text { Simão Jatene } \\
\text { (PSDB) }\end{array}$ & $\begin{array}{l}\text { Decreto estadual } \\
\text { n. } 5.385 \text { de } 4 \text { de } \\
\text { março de } 2005 \\
\end{array}$ & $\begin{array}{l}\text { Institui o Comitê Gestor de Parceria Público-Privada Federal (CGP) } \\
\text { e dá outras providências. }\end{array}$ \\
\hline $\begin{array}{l}\text { Simão Jatene } \\
\text { (PSDB) }\end{array}$ & $\begin{array}{l}\text { Lei estadual n. } \\
7.649 \text { de } 24 \text { de } \\
\text { julho de } 2012 \\
\end{array}$ & $\begin{array}{l}\text { Dispõe sobre normas de licitação e contratação de Parcerias } \\
\text { Público-Privadas (PPP) no âmbito do Estado do Pará e dá outras } \\
\text { providências }\end{array}$ \\
\hline $\begin{array}{l}\text { Simão Jatene } \\
\text { (PSDB) }\end{array}$ & $\begin{array}{l}\text { Decreto n. } 694 \text { de } \\
26 \text { de março de } \\
2013\end{array}$ & $\begin{array}{l}\text { Institui o Comitê de Governança Estadual e os Comitês de } \\
\text { Governança Regionais do Pacto Pela Educação do Pará, e dá outras } \\
\text { providências (revogado pelo Decreto n. } 792 \text { de } 1 \text { de junho de 2013) }\end{array}$ \\
\hline $\begin{array}{l}\text { Simão Jatene } \\
\text { (PSDB) }\end{array}$ & $\begin{array}{l}\text { Decreto n. } 695 \text { de } \\
26 \text { de março de } \\
2013\end{array}$ & $\begin{array}{l}\text { Estabelece critérios para o exercício das funções de Diretores e vice- } \\
\text { diretores das escolas da rede Estadual de Educação de ensino a } \\
\text { serem adotadas pela secretaria de Estado de educação e dá outras } \\
\text { providências }\end{array}$ \\
\hline $\begin{array}{l}\text { Simão Jatene } \\
\text { (PSDB) }\end{array}$ & $\begin{array}{l}\text { Decreto estadual } \\
\text { n. } 713 \text {, de } 1^{\circ} \text { de } \\
\text { abril de } 2013\end{array}$ & $\begin{array}{l}\text { Institui o Programa de Parcerias Público-Privadas (PPP/PA) e } \\
\text { regulamenta o Conselho Gestor de Parcerias Público-Privadas do } \\
\text { Estado do Pará (CGP/PA), para a gestão dos contratos e } \\
\text { procedimentos necessários para a contratação de Parcerias Público- } \\
\text { Privadas no âmbito da Administração Pública do Estado do Pará, } \\
\text { criado pela Lei Estadual n. 7.649, de } 24 \text { de julho de } 2012 \text {. }\end{array}$ \\
\hline $\begin{array}{l}\text { Simão Jatene } \\
\text { (PSDB) }\end{array}$ & $\begin{array}{l}\text { Decreto n. } 792 \text { de } \\
1 \text { de junho de } \\
2013\end{array}$ & $\begin{array}{l}\text { Altera o Decreto n. 694, de } 26 \text { de março de } 2013 \text { que trata do } \\
\text { Comitê de Governança Estadual e os Comitês de Governança } \\
\text { Regionais do Pacto Pela Educação do Pará (revogado pelo Decreto } \\
\text { n. } 1.249 \text {, de } 20 \text { de março de 2015) }\end{array}$ \\
\hline $\begin{array}{l}\text { Simão Jatene } \\
\text { (PSDB) }\end{array}$ & $\begin{array}{l}\text { Resolução n. 01, } \\
\text { de } 19 \text { de junho } \\
2013 \text { (CGP/PA) }\end{array}$ & $\begin{array}{l}\text { Aprova o Regimento Interno do Conselho Gestor de Parcerias } \\
\text { Público-Privadas do Estado do Pará (CGP/PA) }\end{array}$ \\
\hline $\begin{array}{l}\text { Simão Jatene } \\
\text { (PSDB) }\end{array}$ & $\begin{array}{l}\text { Decreto n. } 795 \text {, de } \\
15 \text { de julho de } \\
2013\end{array}$ & $\begin{array}{l}\text { Homologa o Regimento Interno do Conselho Gestor de Parcerias } \\
\text { Público-Privadas do Estado do Pará (CGP/PA) }\end{array}$ \\
\hline $\begin{array}{l}\text { Simão Jatene } \\
\text { (PSDB) }\end{array}$ & $\begin{array}{l}\text { Decreto n. } 1.249 \text {, } \\
\text { de } 20 \text { de março de } \\
2015\end{array}$ & $\begin{array}{l}\text { Institui e disciplina o Sistema de Governança Estadual do Pacto pela } \\
\text { Educação do Pará, e dá outras providências. }\end{array}$ \\
\hline $\begin{array}{l}\text { Simão Jatene } \\
\text { (PSDB) }\end{array}$ & $\begin{array}{l}\text { Lei n. } 8.231 \text { de } 14 \\
\text { de julho de } 2015\end{array}$ & $\begin{array}{l}\text { Altera dispositivo da Lei n. } 7.649 \text {, de } 24 \text { de julho de } 2012 \text {, que } \\
\text { dispõe sobre normas de licitação e contratação de Parcerias Público- } \\
\text { Privadas (PPP) no âmbito do Estado do Pará e dá outras } \\
\text { providências }\end{array}$ \\
\hline $\begin{array}{l}\text { Simão Jatene } \\
\text { (PSDB) }\end{array}$ & $\begin{array}{l}\text { Decreto n. } 1.428, \\
\text { de } 10 \text { de } \\
\text { novembro de } 2015\end{array}$ & $\begin{array}{l}\text { Altera o Decreto n. } 713 \text {, de } 1^{\circ} \text { de abril de } 2013 \text {, que institui o } \\
\text { Programa de Parcerias Público-Privadas (PPP/PA) e regulamenta o } \\
\text { Conselho Gestor de Parcerias Público-Privadas do Estado do Pará } \\
\text { (CGP/PA), para a gestão dos contratos e procedimentos necessários } \\
\text { para a contratação de Parcerias Público-Privadas no âmbito da } \\
\text { Administração Pública do Estado do Pará, criado pela Lei Estadual } \\
\text { n. } 7.649 \text {, de } 24 \text { de julho de } 2012\end{array}$ \\
\hline
\end{tabular}

Fonte: Legislações Estaduais e Vale (2017).

O arcabouço legal aprovado durante o período forneceu as regulamentações necessárias para que a Secretaria de Estado de Educação do Pará (SEDUC-PA) iniciasse o estabelecimento de parcerias com várias instituições do setor privado, tais como:

[...] Instituto Natura, Instituto Airton Sena, Instituto Unibanco, Fundação Roberto Marinho, entre outros que se têm feito presentes na educação pública 
brasileira e paraense, estas têm marcadamente seu interesse em apropriar-se do público e instituir uma lógica privatista, ou seja, de educação como um produto / um serviço e não como um direito de todos (OLIVEIRA, 2017, p. 64).

A concretização dessas parcerias vem ocorrendo com o estabelecimento de convênios, programas $^{4}$, projetos e com a criação de um "Pacto pela Educação no Pará", lançado em 26 de março de 2013 e efetivado por meio do Programa de Melhoria da Qualidade e Expansão da Cobertura da Educação Básica no Pará (PMQEEB/PA), sob o contrato N. 2.933/OC-BR (BRL1327) assinado em 16 de dezembro de 2013, com apoio do Banco Interamericano de Desenvolvimento (BID). Conforme o site ${ }^{5}$ do BID, com o pacto busca-se:

[...] a melhoria da qualidade da educação básica do Estado, a partir de ações voltadas para a qualidade do ensino e capacitação de professores, aperfeiçoamento do currículo e infraestrutura escolar. O programa inova ao compartilhar as iniciativas com diferentes níveis de governo, setor privado e a sociedade civil, por meio de parcerias articuladas pelo BID, que, junto à Secretaria de Estado da Educação (SEDUC), apoiou a preparação das políticas e estratégias para definir o pacto. (BID, 2013, s. p.)

Ainda segundo o mesmo site, além do apoio de articulação, o Banco prepara uma operação com o estado no "[...] valor de US\$ 200 milhões para expandir a cobertura do ensino e alavancar as atividades. A operação terá o aporte de US\$150 milhões de contrapartida do Estado, totalizando investimentos de US\$350 milhões" (BID, 2013, s. p.).

\section{DO PROCESSO DE MERCANTILIZAÇÃO/PRIVATIZAÇÃO DA EDUCAÇÃO BÁSICA PARAENSE}

Da análise dos dados de oferta da educação básica

Segundo a Lei de Diretrizes e Bases da Educação Nacional (LDB n. 9.394/1996), a educação básica brasileira pode ser ofertada por instituições escolares públicas ou privadas (BRASIL, 1996, Art. 19). As mantidas pelo Poder Público podem ser: Federal, quando vinculadas à esfera da União; Estadual, quando sob responsabilidade direta do Estado; ou Municipal, quando sob responsabilidade direta do Município. Todas as instituições escolares vinculadas a estas diferentes dependências administrativas são financiadas pelo Estado, e não cobram matrícula ou mensalidade. Já as instituições escolares privadas são administradas por pessoas físicas ou jurídicas de direito privado, com ou sem finalidade de lucro (BRASIL, 1996, Art. 19, inciso II). As instituições privadas de ensino se enquadrarão nas seguintes categorias:

[...] I - particulares em sentido estrito, assim entendidas as que são instituídas e mantidas por uma ou mais pessoas físicas ou jurídicas de direito privado que não apresentem as características dos incisos abaixo; II - comunitárias, assim entendidas as que são instituídas por grupos de pessoas físicas ou por uma ou mais pessoas jurídicas, inclusive cooperativas educacionais, sem fins lucrativos, que incluam na sua entidade mantenedora representantes da comunidade; III - confessionais, assim entendidas as que são instituídas por grupos de pessoas físicas ou por uma ou

\footnotetext{
4 Ao longo dos anos foram criados vários programas via parceria público-privada no estado: Aceleração da Aprendizagem (Mundiar); Recuperação de Conteúdo (Aprender Mais); Gestão Escolar (Programa Jovem do Futuro); Alfabetização (Pacto Nacional pela Alfabetização na Idade Certa, PNAIC); Escola de Tempo Integral; Sistema Paraense de Avaliação Educacional (SisPAE).

5 Site: https://www.iadb.org/pt/noticias/pacto-pela-educacao-no-para-e-lancado-com-o-apoio-do-bid.
} 
mais pessoas jurídicas que atendem a orientação confessional e ideologia específicas e ao disposto no inciso anterior; IV - filantrópicas, na forma da lei. (BRASIL, 1996, Art. 20)

As instituições privadas com fins lucrativos são aquelas mantidas por ente privado; são as instituições particulares em sentido estrito. As instituições privadas sem fins lucrativos são mantidas por ente privado e podem ser confessionais, comunitárias ou filantrópicas.

No Censo Escolar, os dados referentes às escolas privadas são classificados em: privada conveniada; privada não conveniada sem fins lucrativos; e privada não conveniada com fins lucrativos. De acordo com o Instituto Nacional de Estudos e Pesquisas Educacionais Anísio Teixeira (INEP), as escolas privadas conveniadas são aquelas que possuem:

[...] Acordo celebrado entre poder público e entidades privadas para a realização de objetivos de interesse comum, mediante mútua colaboração. O convênio pode compreender acordo de cooperação técnica, repasse de recursos, prestação de serviços, entre outros. O convênio tratado neste documento é o realizado entre entidade pública - secretaria de educação estadual ou municipal - e entidade privada sem fins lucrativos, com vistas a descentralizar a execução de programa ou projeto na área educacional, com duração definida. Suas regras são disciplinadas no art. 116 da Lei n 8.666/1993, que institui normas para licitações e contratos da administração pública (INEP, 2019, p. 63).

Os dados aqui apresentados têm como objetivo entender o processo de avanço da rede privada de ensino na oferta da educação básica no estado do Pará quando comparada com a ofertada pela rede pública. A Tabela 2, a seguir, apresenta dados de matrícula da educação básica por dependência administrativa no estado do Pará.

Tabela 2: Número de matrículas da educação básica por dependência administrativa (federal, estadual, municipal, privada) — Pará, 2013 a 2018

\begin{tabular}{|c|c|c|c|c|c|c|}
\hline \multirow{2}{*}{$\begin{array}{c}\text { Anos } \\
\mathbf{2 0 1 3} \mathbf{2 0 1 8}\end{array}$} & Total & Federal & Estadual & Municipal & Privada & $\begin{array}{c}\text { \% Mat. } \\
\text { Privada }\end{array}$ \\
\cline { 2 - 7 } & 2.429 .880 & 9.395 & 644.222 & 1.551 .404 & 224.759 & 9,25 \\
\hline 2013 & 2.414 .952 & 8.955 & 632.309 & 1.536 .890 & 236.798 & 9,81 \\
\hline 2014 & 2.375 .563 & 11.005 & 621.106 & 1.509 .903 & 233.549 & 9,83 \\
\hline 2015 & 2.353 .582 & 11.302 & 611.508 & 1.498 .132 & 232.640 & 9,88 \\
\hline 2016 & 2.339 .648 & 12.049 & 589.280 & 1.507 .319 & 231.000 & 9,87 \\
\hline 2017 & 2.328 .439 & 14.040 & 584.949 & 1.495 .468 & 233.982 & 10,05 \\
\hline 2018 & $\mathbf{- 4 , 1 7}$ & $\mathbf{4 9 , 4 4}$ & $\mathbf{- 9 , 2 0}$ & $\mathbf{- 3 , 6 1}$ & $\mathbf{4 , 1 0}$ & \\
\hline $\mathbf{0}$ & & &
\end{tabular}

Fonte: Elaborado pelo Laboratório de Dados Educacionais/UFPR a partir dos microdados do Censo Escolar / INEP

O movimento da matrícula no período de 2013 a 2018 revela redução de $-4,17 \%$ do total de matrículas; redução das matrículas na rede municipal (-3,61\%); queda acentuada das matrículas da rede estadual $(-9,20 \%)$; e crescimento da rede privada na casa dos $4 \%$.

Ao analisarmos os dados de matrícula da rede privada de ensino da educação básica por etapa e modalidade de ensino no estado do Pará, percebemos que há variações entre as etapas e modalidades no incremento do setor privado: 
Tabela 3: Número de matrículas da educação básica por etapas e modalidades de ensino na rede privada (privada conveniada, privada não conveniada sem fins lucrativos, privada não conveniada com fins lucrativos) — Pará, 2013 a 2018

\begin{tabular}{|c|c|c|c|c|c|c|}
\hline \multirow{2}{*}{$\begin{array}{c}\text { Anos } \\
\mathbf{2 0 1 3 / 2 0 1 8}\end{array}$} & Creche & Pré-Escola & EF & EM & EJA & $\begin{array}{c}\text { Ed } \\
\text { Profissional }\end{array}$ \\
\hline 2013 & 8.118 & 30.158 & 125.253 & 34.005 & 11.187 & 16.038 \\
\hline 2014 & 8.353 & 31.139 & 127.929 & 34.885 & 14.559 & 19.446 \\
\hline 2015 & 8.801 & 28.598 & 128.158 & 35.780 & 13.384 & 18.828 \\
\hline 2016 & 8.869 & 27.356 & 130.895 & 35.083 & 14.698 & 15.739 \\
\hline 2017 & 10.307 & 27.917 & 126.888 & 33.059 & 14.809 & 18.020 \\
\hline 2018 & 10.219 & 28.640 & 128.005 & 29.773 & 17.274 & 20.071 \\
\hline $\mathbf{\%}$ & $\mathbf{2 5 , 8 8}$ & $\mathbf{- 5 , 0 3}$ & $\mathbf{2 , 2 0}$ & $\mathbf{- 1 2 , 4 5}$ & $\mathbf{5 4 , 4 1}$ & $\mathbf{2 5 , 1 5}$ \\
\hline
\end{tabular}

Fonte: Elaborado pelo Laboratório de Dados Educacionais/UFPR a partir dos microdados do Censo Escolar / INEP

No estado do Pará, a rede privada de ensino apresenta tendência de crescimento, ou seja, amplia sua atuação no atendimento à creche em 25,88\%; ao ensino fundamental em 2,20\%; apresenta aumento expressivo no atendimento à EJA de 54,41\%; e no atendimento à educação profissional $25,15 \%$. Apenas registrou queda no atendimento da pré-escola $(-5,03 \%)$ e no ensino médio $(-12,45 \%)$.

Ao centrarmos nosso olhar para o atendimento às matrículas da educação básica realizado pela rede privada de ensino, nos diferentes tipos de instituição no Pará (privada conveniada, privada não conveniada sem fins lucrativos e privada não conveniada com fins lucrativos), vamos perceber que as matrículas privadas conveniadas registram quedas elevadas no atendimento do ensino fundamental (-86,74\%); do ensino médio (-89,52\%); do atendimento à EJA (-82,16\%); e no atendimento à educação profissional $(-98,51)$. Apenas houve crescimento no atendimento à creche $(37,68 \%)$ e à pré-escola $(7,69 \%)$. Cabe lembrar que neste período o Fundo de Manutenção e Desenvolvimento da Educação Básica e de Valorização dos Profissionais da Educação (FUNDEB) aceitou a inclusão das matrículas conveniadas entre os fatores de ponderação no cálculo para distribuição da receita.

Tabela 4: Número de matrículas da educação básica por etapas e modalidades de ensino rede privada (privada conveniada) - Pará, 2013 a 2018

\begin{tabular}{|c|c|c|c|c|c|c|}
\hline \multirow{2}{*}{$\begin{array}{c}\text { Anos } \\
\mathbf{2 0 1 3 / 2 0 1 8}\end{array}$} & Creche & $\begin{array}{c}\text { Pré- } \\
\text { Escola }\end{array}$ & EF & EM & EJA & $\begin{array}{c}\text { Ed } \\
\text { Profissional }\end{array}$ \\
\hline 2013 & 1.059 & 2.355 & 10.174 & 3.626 & 1.312 & 1.678 \\
\hline 2014 & 962 & 2.767 & 12.046 & 3.952 & 2.287 & 3.326 \\
\hline 2015 & 789 & 2.258 & 10.075 & 3.558 & 3.342 & 1.400 \\
\hline 2016 & 628 & 1.696 & 7.405 & 1.658 & 1.850 & 411 \\
\hline 2017 & 491 & 1.424 & 5.840 & 1.316 & 1.458 & 299 \\
\hline 2018 & 1.458 & 2.536 & 1.349 & 380 & 234 & 25 \\
\hline $\mathbf{\%}$ & $\mathbf{3 7 , 6 8}$ & $\mathbf{7 , 6 9}$ & $\mathbf{- 8 6 , 7 4}$ & $\mathbf{- 8 9 , 5 2}$ & $\mathbf{- 8 2 , 1 6}$ & $\mathbf{- 9 8 , 5 1}$ \\
\hline
\end{tabular}

Fonte: Elaborado pelo Laboratório de Dados Educacionais/UFPR a partir dos microdados do Censo Escolar / INEP

Quando voltamos o nosso olhar para as matrículas da educação básica por etapas e modalidades de ensino da rede privada não conveniada sem fins lucrativos, percebemos que as matrículas nas instituições privadas sem fins lucrativos tiveram tendência completamente oposta à 
apresentada pelas matrículas privadas conveniadas. Registraram crescimentos expressivos e, o que chama a atenção, o crescimento se deu em quase todas as etapas e modalidades de ensino durante o período analisado.

Tabela 5: Número de matrículas da educação básica por etapas e modalidades de ensino rede privada (privada não conveniada sem fins lucrativos) - Pará, 2013 a 2018

\begin{tabular}{|c|c|c|c|c|c|c|}
\hline \multirow{2}{*}{$\begin{array}{c}\text { Anos } \\
\mathbf{2 0 1 3 / 2 0 1 8}\end{array}$} & Creche & Pré-Escola & EF & EM & EJA & $\begin{array}{c}\text { Ed } \\
\text { Profissional }\end{array}$ \\
\hline 2013 & 405 & 869 & 8.613 & 3.072 & 289 & 14 \\
\hline 2014 & 451 & 1.033 & 8.330 & 2.934 & 295 & 13 \\
\hline 2015 & 530 & 1.221 & 9.255 & 3.442 & 459 & 24 \\
\hline 2016 & 498 & 1.194 & 10.255 & 4.126 & 751 & 297 \\
\hline 2017 & 496 & 1.207 & 10.125 & 3.823 & 453 & 176 \\
\hline 2018 & 756 & 2.037 & 12.971 & 3.482 & 608 & 216 \\
\hline $\mathbf{\%}$ & $\mathbf{8 6 , 6 7}$ & $\mathbf{1 3 4 , 4 0}$ & $\mathbf{5 0 , 6 0}$ & $\mathbf{1 3 , 3 5}$ & $\mathbf{1 1 0 , 3 8}$ & $\mathbf{1 . 4 4 2 , 8 6}$ \\
\hline
\end{tabular}

Fonte: Elaborado pelo Laboratório de Dados Educacionais/UFPR a partir dos microdados do Censo Escolar / INEP

Quanto às matrículas da educação básica por etapas e modalidades de ensino na rede privada não conveniada com fins lucrativos, no estado do Pará, a Tabela 6, a seguir, revelou que na rede privada não conveniada com fins lucrativos também houve crescimento registrado na creche $(20,30 \%)$; no ensino fundamental $(6,78 \%)$; na EJA $(71,42 \%)$; e nas matrículas da educação profissional, que cresceu $38,23 \%$. Houve registro de queda somente nas matrículas da pré-escola ($25,50 \%)$ e do ensino médio $(-5,11 \%)$.

Tabela 6: Número de matrículas da educação básica por etapas e modalidades de ensino rede privada (privada não conveniada com fins lucrativos) - Pará, 2013 a 2018

\begin{tabular}{|c|c|c|c|c|c|c|}
\hline \multirow{2}{*}{$\begin{array}{c}\text { Anos } \\
\mathbf{2 0 1 3 / 2 0 1 8}\end{array}$} & Creche & Pré-Escola & EF & EM & EJA & $\begin{array}{c}\text { Ed } \\
\text { Profissional }\end{array}$ \\
\hline 2013 & 6.654 & 26.934 & 106.466 & 27.307 & 9.586 & 14.346 \\
\hline 2014 & 6.940 & 27.339 & 107.553 & 27.999 & 12.464 & 16.107 \\
\hline 2015 & 7.482 & 25.119 & 108.828 & 28.780 & 9.583 & 17.404 \\
\hline 2016 & 7.743 & 24.466 & 113.235 & 29.299 & 12.097 & 15.031 \\
\hline 2017 & 9.320 & 25.286 & 110.923 & 27.920 & 12.898 & 17.545 \\
\hline 2018 & 8.005 & 24.067 & 113.685 & 25.911 & 16.432 & 19.830 \\
\hline $\mathbf{\%}$ & $\mathbf{2 0 , 3 0}$ & $\mathbf{- 2 5 , 5 0}$ & $\mathbf{6 , 7 8}$ & $\mathbf{- 5 , 1 1}$ & $\mathbf{7 1 , 4 2}$ & $\mathbf{3 8 , 2 3}$ \\
\hline
\end{tabular}

Fonte: Elaborado pelo Laboratório de Dados Educacionais/UFPR a partir dos microdados do Censo Escolar / INEP

Quando voltamos nossa atenção para as matrículas da rede pública de ensino, especificamente as matrículas pertencentes à rede estadual de ensino do Pará, nas diferentes etapas e modalidades de ensino, percebemos tendência inversa à apresentada pela rede privada de ensino no período analisado, conforme podemos constatar na Tabela 7 a seguir: 
DOI: https://doi.org/10.12957/teias.2020.49562

Tabela 7: Número de matrículas da educação básica por etapas e modalidades de ensino na rede estadual - Pará, 2013 a 2018

\begin{tabular}{|c|c|c|c|c|c|c|}
\hline \multirow{2}{*}{$\begin{array}{c}\text { Anos } \\
\mathbf{2 0 1 3 / 2 0 1 8}\end{array}$} & Creche & Pré-Escola & EF & EM & EJA & $\begin{array}{c}\text { Ed } \\
\text { Profissional }\end{array}$ \\
\cline { 2 - 7 } & 117 & 447 & 228.363 & 318.647 & 94.403 & 2.345 \\
\hline 2013 & 133 & 440 & 216.975 & 320.793 & 91.367 & 2.601 \\
\hline 2014 & 137 & 356 & 211.587 & 320.071 & 85.415 & 3.540 \\
\hline 2015 & 14 & 18 & 204.131 & 325.089 & 78.022 & 4.234 \\
\hline 2016 & 14 & 30 & 191.889 & 320.765 & 72.218 & 4.364 \\
\hline 2017 & 29 & 45 & 188.173 & 323.205 & 68.016 & 5.481 \\
\hline 2018 & $\mathbf{7 5 , 2 1}$ & $\mathbf{- 8 9 , 9 3}$ & $\mathbf{- 1 7 , 5 0}$ & $\mathbf{1 , 4 3}$ & $\mathbf{- 2 7 , 9 5}$ & $\mathbf{1 3 3 , 7 3}$ \\
\hline $\mathbf{0}$ & & & & & \\
\hline
\end{tabular}

Fonte: Elaborado pelo Laboratório de Dados Educacionais/UFPR a partir dos microdados do Censo Escolar / INEP

A rede estadual de ensino apresentou queda no atendimento de matrículas da creche ($75,21 \%)$; da pré-escola $(-89,93)$; do ensino fundamental $(-17,50 \%)$; e da educação e jovens e adultos $(-27,95 \%)$. Crescimento pouco expressivo no ensino médio (de apenas 1,43\%), etapa de atendimento obrigatório dos estados e crescimento elevado no atendimento à educação profissional $(133,73 \%)$.

No caso da rede pública de ensino municipal, percebemos tendência de queda ainda mais preocupante que a apresentada pela rede pública estadual, conforme podemos observar na Tabela 8, a seguir:

Tabela 8: Número de matrículas da educação básica por etapas e modalidades de ensino na rede municipal — Pará, 2013 a 2018

\begin{tabular}{|c|c|c|c|c|c|c|}
\hline \multirow{2}{*}{$\begin{array}{c}\text { Anos } \\
\mathbf{2 0 1 3 / 2 0 1 8}\end{array}$} & Creche & Pré-Escola & EF & EM & EJA & $\begin{array}{c}\text { Ed } \\
\text { Profissional }\end{array}$ \\
\hline 2013 & 38.088 & 208.452 & 1.156 .405 & 181 & 148.278 & - \\
\hline 2014 & 43.068 & 210.678 & 1.150 .272 & 201 & 132.671 & - \\
\hline 2015 & 49.228 & 204.685 & 1.133 .861 & 138 & 121.991 & - \\
\hline 2016 & 54.540 & 206.231 & 1.128 .966 & 131 & 108.264 & - \\
\hline 2017 & 60.796 & 207.424 & 1.133 .830 & 204 & 105.065 & - \\
\hline 2018 & 66.856 & 208.318 & 1.121 .838 & 124 & 98.332 & - \\
\hline $\mathbf{0}$ & $\mathbf{7 5 , 5 3}$ & $\mathbf{- 0 , 0 6}$ & $\mathbf{- 2 , 9 9}$ & $\mathbf{- 3 1 , 4 9}$ & $\mathbf{- 3 3 , 6 8}$ & - \\
\hline
\end{tabular}

Fonte: Elaborado pelo Laboratório de Dados Educacionais/UFPR a partir dos microdados do Censo Escolar / INEP

A rede municipal de ensino reduziu suas matrículas na pré-escola $(-0,06 \%)$ e no ensino fundamental $(-2,99 \%)$ - etapas de ensino de atuação prioritária do município. Apresentou queda de matrículas também no ensino médio (-31,49\%); na educação de jovens e adultos $(-33,68 \%)$; e não registrou atendimento à educação profissional. Durante o período analisado, a rede municipal de ensino apresentou crescimento das matrículas apenas na creche $(75,53 \%)$.

No que se refere aos números de escolas / estabelecimentos, percebemos queda no número total de estabelecimentos; queda nas redes estadual e municipal; e crescimento do número de escolas apenas da rede federal e privada de ensino, conforme revela a Tabela 9, seguinte: 
DOI: https://doi.org/10.12957/teias.2020.49562

Tabela 9: Número de escolas/estabelecimentos da educação básica por dependência administrativa (federal, estadual, municipal, privada) — Pará, 2013 a 2018

\begin{tabular}{|c|c|c|c|c|c|c|}
\hline \multirow{2}{*}{$\begin{array}{c}\text { Anos } \\
\mathbf{2 0 1 3 / 2 0 1 8}\end{array}$} & Total & Federal & Estadual & Municipal & Privada & $\begin{array}{c}\text { \% Escola } \\
\text { Privada }\end{array}$ \\
\cline { 2 - 7 } & 11.614 & 16 & 913 & 9.790 & 895 & 7,71 \\
\hline 2013 & 11,437 & 18 & 891 & 9.614 & 914 & 7,99 \\
\hline 2014 & 11.227 & 22 & 875 & 9.457 & 873 & 7,78 \\
\hline 2015 & 11.115 & 24 & 856 & 9.339 & 896 & 8,06 \\
\hline 2016 & 10.972 & 23 & 886 & 9.172 & 891 & 8,12 \\
\hline 2017 & 10.800 & 24 & 893 & 8.963 & 920 & 8,52 \\
\hline 2018 & $\mathbf{- 7 , 0 1}$ & $\mathbf{5 0 , 0 0}$ & $\mathbf{- 2 , 1 9}$ & $\mathbf{- 8 , 4 5}$ & $\mathbf{2 , 7 9}$ & \\
\hline $\mathbf{0}$ & & &
\end{tabular}

Fonte: Elaborado pelo Laboratório de Dados Educacionais/UFPR a partir dos microdados do Censo Escolar / INEP

Conforme revelado pelos dados da Tabela, as redes estadual e municipal que apresentaram queda no número de matrículas, também apresentaram queda no número de escolas de $-2,19$ e 8,45 , respectivamente. A rede privada, por outro lado, passa de um total de $7 \%$ das escolas para responder por um total de $8,52 \%$. Ainda que estes sejam dados apenas de acesso, há evidências de uma movimentação efetiva em relação ao provimento da oferta na direção de maior participação do setor privado no estado do Pará.

Cabe agora observar os elementos relativos ao financiamento da educação implicados neste período.

Da análise dos dados do Orçamento Estadual (PA) e dos componentes de privatização dos gastos orçamentários

O financiamento público da educação no Brasil foi consolidado no texto da CF 1988 (Art. 212) e no texto da LDB (n. 9.424/1996) nos Artigos 68 a 77 que estabelecem, entre outras coisas, que os recursos públicos, além de financiar a educação pública, também podem ser aplicados no setor privado da educação, em escolas "comunitárias, confessionais ou filantrópicas" (BRASIL, 1996, Art. 77). Os dados de receita e despesas públicas do Estado, de um modo geral, inclusive da educação, compõem o orçamento público, peça técnica e formal de cunho político que nos ajuda a perceber a direção e a forma de ação do Estado nas suas prioridades de políticas públicas (SALVADOR, 2017).

Assim, esta seção tem por objetivo investigar os gastos com a educação por função e subfunção no estado do Pará e identificar o montante dos recursos transferidos para as entidades privadas sem fins lucrativos e os recursos gastos com convênios registrados no orçamento / balanço do estado. A análise dos gastos públicos do estado do Pará, por função, no período de 2013 a 2018, conforme apresentados na Tabela 10, a seguir, permite algumas observações sobre as prioridades nas despesas públicas.

Tabela 10: Gastos públicos orçamentários por função - Pará - 2013 a 2018

\begin{tabular}{|c|c|c|c|c|c|c|}
\hline Função/ano & $\mathbf{2 0 1 3}$ & $\mathbf{2 0 1 4}$ & $\mathbf{2 0 1 5}$ & $\mathbf{2 0 1 6}$ & $\mathbf{2 0 1 7}$ & $\mathbf{2 0 1 8}$ \\
\hline Legislativa & $788.735 .698,22$ & $809.924 .636,18$ & $850.223 .941,41$ & $864.175 .376,83$ & $809.251 .744,94$ & $805.090 .137,64$ \\
\hline Judiciária & $1.011 .239 .836,55$ & $1.138 .924 .036,51$ & $1.174 .626 .867,01$ & $1.134 .779 .246,49$ & $1.138 .625 .724,09$ & $1.156 .408 .357,15$ \\
\hline Justiça & $847.970 .950,61$ & $962.998 .603,32$ & $1.056 .301 .649,35$ & $1.028 .046 .598,28$ & $1.085 .306 .843,17$ & $1.140 .519 .356,40$ \\
\hline Administração & $762.910 .915,30$ & $928.319 .400,50$ & $958.877 .219,50$ & $1.285 .996 .061,90$ & $1.215 .938 .493,94$ & $1.453 .355 .016,35$ \\
\hline Seg. Pública & $2.257 .094 .477,57$ & $2.529 .401 .456,50$ & $2.684 .594 .845,03$ & $2.539 .527 .649,74$ & $2.500 .597 .356,82$ & $2.831 .292 .009,49$ \\
\hline Assis. social & $1.031 .417 .605,77$ & $1.132 .378 .876,06$ & $1.256 .432 .945,65$ & $1.197 .934 .086,25$ & $1.373 .520 .717,78$ & $1.035 .105 .709,72$ \\
\hline Prev. Social & $3.288 .939 .366,12$ & $3.528 .885 .239,86$ & $3.829 .432 .936,25$ & $3.600 .522 .995,59$ & $3.458 .576 .416,41$ & $3.631 .719 .141,82$ \\
\hline
\end{tabular}


DOI: https://doi.org/10.12957/teias.2020.49562

\begin{tabular}{|c|c|c|c|c|c|c|}
\hline Saúde & $2.680 .995 .259,69$ & $2.772 .699 .898,56$ & $2.822 .456 .167,85$ & $2.738 .327 .066,28$ & $2.816 .630 .786,85$ & $3.271 .693 .236,20$ \\
\hline Trabalho & $14.443 .196,09$ & $9.435 .271,35$ & $5.753 .060,01$ & $10.073 .075,74$ & $11.315 .167,43$ & $5.920 .120,14$ \\
\hline Educação & 3.717.157.217,68 & $3.950 .815 .651,89$ & $4.066 .948 .674,94$ & 3.823.280.533,96 & 3.818.394.779,64 & 4.072.270.713,99 \\
\hline Cultura & $162.262 .610,05$ & $162.082 .056,73$ & $162.246 .636,16$ & $155.708 .142,93$ & $130.041 .046,45$ & $116.083 .598,33$ \\
\hline Cidadania & $43.759 .699,24$ & $38.995 .153,98$ & $41.789 .970,30$ & $47.036 .308,04$ & $51.332 .457,43$ & $63.873 .939,36$ \\
\hline Urbanismo & $111.342 .760,91$ & $109.401 .139,75$ & $206.573 .208,10$ & $86.233 .693,96$ & $28.633 .447,45$ & $334.095 .937,50$ \\
\hline Habitação & $117.490 .317,15$ & $107.836 .627,75$ & $97.079 .504,42$ & $78.830 .624,92$ & $85.774 .990,74$ & $75.360 .136,30$ \\
\hline Saneamento & $286.682 .769,34$ & $275.578 .646,29$ & $48.124 .955,51$ & $48.553 .711,80$ & $31.845 .757,27$ & $58.459 .120,97$ \\
\hline $\begin{array}{c}\text { Gestão } \\
\text { Ambiental }\end{array}$ & $88.610 .637,69$ & $102.517 .028,36$ & $96.234 .116,19$ & $97.970 .735,94$ & 111.117.353,66 & $126.488 .899,34$ \\
\hline $\begin{array}{c}\text { Ciência } \\
\text { Tecnologia }\end{array}$ & $66.385 .984,24$ & $87.708 .739,75$ & $55.993 .672,91$ & $46.902 .537,87$ & $50.698 .116,68$ & $39.263 .893,31$ \\
\hline Agricultura & $317.457 .010,73$ & $330.886 .566,44$ & $300.576 .184,11$ & $271.995 .277,61$ & $248.651 .475,71$ & $287.679 .839,24$ \\
\hline Org. Agrária & $23.844 .620,83$ & $25.183 .034,32$ & $21.357 .299,72$ & $25.422 .201,92$ & $27.146 .509,74$ & $21.348 .540,44$ \\
\hline Indústria & $35.726 .860,03$ & $45.497 .419,02$ & $51.571 .258,04$ & $40.844 .572,33$ & $44.279 .827,33$ & $52.381 .797,12$ \\
\hline Comer. Serviços & $159.907 .827,07$ & $164.861 .572,32$ & $52.263 .847,96$ & $152.203 .657,94$ & $169.775 .736,96$ & $167.358 .458,09$ \\
\hline Comunicações & $94.270 .186,87$ & $83.339 .109,48$ & $77.066 .137,17$ & $76.180 .570,94$ & $80.225 .238,01$ & $67.351 .232,32$ \\
\hline Energia & $213.200,69$ & $355.250,42$ & $700.981,69$ & $16.770,52$ & $9.142,07$ & $6.377,16$ \\
\hline Transportes & $811.410 .638,10$ & $751.617 .574,78$ & $869.525 .563,40$ & $451.292 .520,28$ & $521.421 .937,07$ & $864.522 .049,74$ \\
\hline $\begin{array}{l}\text { Desporto e } \\
\text { Lazer }\end{array}$ & $51.388 .602,50$ & $112.785 .837,99$ & $69.422 .783,75$ & $53.992 .569,93$ & $55.071 .952,34$ & $57.213 .598,98$ \\
\hline $\begin{array}{l}\text { Encargos } \\
\text { Especiais }\end{array}$ & $4.744 .058 .014,04$ & $4.835 .450 .245,39$ & $5.264 .553 .928,49$ & $4.533 .954 .720,76$ & $4.202 .288 .566,32$ & 4.666.717.091,65 \\
\hline $\begin{array}{c}\text { Part. \% } \\
\text { Encargos } \\
\text { Especiais }\end{array}$ & 20,17 & 19,34 & 20,15 & 18,59 & 17,46 & 17,68 \\
\hline $\begin{array}{l}\text { Part. \% da } \\
\text { Educação }\end{array}$ & 15,81 & 15,80 & 15,57 & 15,68 & 15,87 & 15,42 \\
\hline Total & $23.515 .716 .263,10$ & $24.997 .879 .073,50$ & $26.120 .728 .354,95$ & $24.389 .801 .308,80$ & 24.066.471.586,30 & 26.401.578.308,75 \\
\hline
\end{tabular}

Fonte: - Balanço Geral do Estado - Despesas Liquidadas - exercícios 2013 a 2018. Dados Deflacionados.

A prioridade política do estado do Pará, no período em estudo, tem sido com os gastos com encargos especiais - despesas a que não se pode associar um bem ou serviço a ser gerado no processo produtivo corrente, o que inclui as participações acionárias e, especialmente, os encargos e amortização da dívida, indenizações, royalties e aportes em organismos internacionais, entre outras ${ }^{6}$ (PARÁ, 2014, p. 131). Os gastos com encargos especiais, no período analisado, representaram em média 18,90\% dos gastos totais do estado, o que demonstra, de forma inequívoca, a opção em privilegiar o capital, o econômico, em detrimento do social.

Em que pesem os gastos em educação terem registrado aumento de 9,55\%, o que em números absolutos representaria um acréscimo de $\mathrm{R} \$ 355.113 .496,31$, no que se refere à participação da educação, em termos percentuais, no orçamento público do estado, os dados apresentados revelam que esta vem perdendo importância ao longo do período analisado. Em 2013, representava $15,81 \%$ dos gastos totais e, em 2018, passou a representar $15,42 \%$ dos gastos totais.

A Tabela 11, a seguir, apresenta os gastos públicos orçamentários por subfunção da função educação. Essa análise mais detalhada nos ajudará a entender melhor os gastos nas diferentes etapas e modalidades de ensino no Pará.

\footnotetext{
${ }^{6}$ A utilização dessa função requer o uso das subfunções típicas, conforme lista a seguir: 841 - Refinanciamento da Dívida Interna; 842 - Refinanciamento da Dívida Externa; 843 - Serviço da Dívida Interna; 844 - Serviço da Dívida Externa; 845 - Outras Transferências; 846 - Outros Encargos Especiais, entre outros. Fonte: http://www.portaltransparencia.gov.br/pagina-interna/603240-encargos-especiais.
} 
Tabela 11: Gastos públicos orçamentários com a função educação e por subfunção - Pará, 2013 a 2018

\begin{tabular}{|c|c|c|c|c|c|c|c|c|c|c|c|}
\hline $\begin{array}{l}\text { Funç } \\
\text { ão e } \\
\text { Sub- } \\
\text { fun- } \\
\text { ção } \\
\text { Anos } \\
2013 \\
\mathbf{2 0 1 8} \\
\end{array}$ & Educação & $\begin{array}{c}\text { Educaçã } \\
\text { o Infantil } \\
\text { (1) }\end{array}$ & $\begin{array}{c}\text { Ensino } \\
\text { Fundamen- } \\
\text { tal } \\
(2)\end{array}$ & $\begin{array}{l}\text { Ensino } \\
\text { Médio } \\
\text { (3) }\end{array}$ & $\begin{array}{c}\text { Ensino } \\
\text { Profissio } \\
\text { nal }\end{array}$ & EJA & $\begin{array}{c}\text { Ed. } \\
\text { Especial }\end{array}$ & $\begin{array}{l}\text { Ensino } \\
\text { Superior }\end{array}$ & $\begin{array}{c}\text { Demais } \\
\text { Subfunções }\end{array}$ & $\begin{array}{c}\text { Total } \\
\text { Educação } \\
\text { Básica } \\
(1)+(2)+(3)\end{array}$ & $\begin{array}{c}\text { Part } \\
\% \\
\text { da } \\
\text { Ed. } \\
\text { Bási } \\
\text { ca }\end{array}$ \\
\hline 2013 & $\begin{array}{c}3.717 .157 .21 \\
7,68\end{array}$ & $\begin{array}{c}7.804 .370 \\
66\end{array}$ & $\begin{array}{c}1.190 .340 .49 \\
6,76\end{array}$ & $\begin{array}{c}1.361 .187 .24 \\
9,45\end{array}$ & $\begin{array}{c}37.772 .97 \\
6,53\end{array}$ & $\begin{array}{c}196.373 .88 \\
6,36\end{array}$ & $\begin{array}{c}2.822 .076 \\
, 55\end{array}$ & $\begin{array}{c}236.101 .59 \\
0,76\end{array}$ & $\begin{array}{c}684.754 .570 \\
61\end{array}$ & $\begin{array}{c}2.559 .332 .11 \\
6,87 \\
\end{array}$ & 68,85 \\
\hline 2014 & $\begin{array}{c}3.950 .748 .26 \\
4,50 \\
\end{array}$ & $\begin{array}{c}21.746 .84 \\
7,41 \\
\end{array}$ & $\begin{array}{c}1.190 .412 .49 \\
5,97 \\
\end{array}$ & $\begin{array}{c}1.526 .309 .03 \\
2,28 \\
\end{array}$ & $\begin{array}{c}34.071 .31 \\
6,21 \\
\end{array}$ & $\begin{array}{c}210.934 .58 \\
4,63 \\
\end{array}$ & $\begin{array}{c}1.993 .826 \\
, 40 \\
\end{array}$ & $\begin{array}{c}259.244 .06 \\
4,62 \\
\end{array}$ & $\begin{array}{c}\text { 706.036.096, } \\
99 \\
\end{array}$ & $\begin{array}{l}2.738 .468 .37 \\
5,66\end{array}$ & 69,32 \\
\hline 2015 & $\begin{array}{c}4.070 .616 .99 \\
8,07\end{array}$ & $\begin{array}{c}27.783 .26 \\
1,83\end{array}$ & $\begin{array}{c}1.201 .411 .86 \\
8,90\end{array}$ & $\begin{array}{c}1.493 .009 .66 \\
7,61\end{array}$ & $\begin{array}{c}21.487 .60 \\
2,31\end{array}$ & $\begin{array}{c}215.197 .52 \\
8,22\end{array}$ & $\begin{array}{c}359.971,2 \\
8\end{array}$ & $\begin{array}{c}266.437 .69 \\
9,19\end{array}$ & $\begin{array}{c}844.929 .398, \\
72\end{array}$ & $\begin{array}{l}2.722 .204 .79 \\
8,34\end{array}$ & 66,87 \\
\hline 2016 & $\begin{array}{c}3.816 .519 .04 \\
3,49\end{array}$ & $\begin{array}{c}21.182 .41 \\
9,60\end{array}$ & $\begin{array}{c}1.103 .888 .30 \\
4,74\end{array}$ & $\begin{array}{c}1.281 .019 .56 \\
0,06\end{array}$ & $\begin{array}{c}23.264 .48 \\
7,99\end{array}$ & $\begin{array}{c}169.848 .78 \\
7,01\end{array}$ & 0,00 & $\begin{array}{c}35.053 .272, \\
13\end{array}$ & $\begin{array}{c}1.182 .262 .22 \\
2,18\end{array}$ & $\begin{array}{l}2.406 .090 .28 \\
4,40\end{array}$ & 63,04 \\
\hline 2017 & $\begin{array}{c}3.817 .920 .91 \\
0,04\end{array}$ & $1.441,84$ & $\begin{array}{c}1.021 .528 .58 \\
8,84\end{array}$ & $\begin{array}{c}1.260 .827 .11 \\
5,56\end{array}$ & $78.789,64$ & $\begin{array}{c}150.782 .01 \\
7,82 \\
\end{array}$ & 0,00 & $\begin{array}{c}34.991 .367, \\
42\end{array}$ & $\begin{array}{c}1.343 .636 .38 \\
8,57 \\
\end{array}$ & $\begin{array}{l}2.282 .357 .14 \\
6,24\end{array}$ & 59,78 \\
\hline 2018 & $\begin{array}{c}4.105 .343 .34 \\
\quad 4,11 \\
\end{array}$ & $\begin{array}{c}\text { 1.222.974, } \\
96\end{array}$ & $\begin{array}{c}\text { 982.958.117, } \\
81 \\
\end{array}$ & $\begin{array}{c}1.286 .713 .35 \\
7,85 \\
\end{array}$ & $\begin{array}{c}18.060 .71 \\
9,46 \\
\end{array}$ & $\begin{array}{c}193.851 .05 \\
3,33 \\
\end{array}$ & $\begin{array}{c}806.218,8 \\
1 \\
\end{array}$ & $\begin{array}{c}\text { 32.325.686, } \\
83 \\
\end{array}$ & $\begin{array}{c}1.630 .907 .29 \\
7,64 \\
\end{array}$ & $\begin{array}{l}2.270 .894 .45 \\
0,62\end{array}$ & 55,32 \\
\hline$\%$ & & $-98,43$ & $-17,42$ & $-7,45$ & $-52,19$ & $-1,28$ & $-71,43$ & $-86,31$ & 237,17 & $-11,27$ & \\
\hline
\end{tabular}

Fonte: SIOPE - Despesas Liquidadas - dados deflacionados.

Em que pesem os gastos com a função educação terem registrado aumento ao longo do período estudado, esse aumento não se fez refletir em nenhuma das etapas de ensino da educação básica (que caiu -11,27\%), e tampouco nas demais modalidades de ensino. A participação da educação básica nos gastos totais da função educação caiu de $68,85 \%$ para $55,32 \%$. Os gastos com a educação infantil caíram quase em sua totalidade (-98,43\%); com o ensino fundamental $(-17,42 \%)$; com o ensino médio $(-7,45 \%)$; com o ensino profissional $(-52,19 \%)$; com a educação de jovens e adultos (-1,28\%); e com a educação especial (-71,43\%).

Por outro lado, os gastos com as demais subfunções cresceram $237,17 \%$ e incluem despesas com: Desenvolvimento científico: Vinculação à contribuição do salário educação; Inativos; Desenvolvimento tecnológico e engenharia; Programa Dinheiro Direto na Escola (PDDE), Programa Nacional de Apoio ao Transporte Escolar (PNATE), Programa Nacional de Alimentação Escolar (PNAE); outras transferências de recursos do Fundo Nacional de Desenvolvimento da Educação (FNDE); e os gastos referentes às transferências de convênioseducação.

No que se refere mais especificamente aos gastos com a subfunção transferências de convênios-educação, que aparecem nos gastos do estado a partir de 2016, os dados apresentados na Tabela 12, a seguir, revelam:

Tabela 12: Despesas liquidadas com subfunção transferências de convênios - educação - Pará 2016 a 2018

\begin{tabular}{|l|c|c|c|}
\hline $\begin{array}{c}\text { Função e Subfunção } \\
\text { ANOS 2016/2018 }\end{array}$ & Educação & $\begin{array}{c}\text { Transferências de } \\
\text { Convênios }\end{array}$ & $\begin{array}{c}\text { Participação } \\
\mathbf{\%}\end{array}$ \\
\hline 2016 & $3.816 .519 .043,49$ & $49.946 .738,87$ & $\mathbf{1 , 3}$ \\
\hline 2017 & $3.817 .920 .910,04$ & $32.494 .503,78$ & $\mathbf{0 , 8 5}$ \\
\hline 2018 & $4.105 .343 .344,11$ & $313.584 .128,22$ & $\mathbf{7 , 6}$ \\
\hline$\%$ & & 527,84 & \\
\hline
\end{tabular}

Fonte: SIOPE - Despesas Liquidadas - dados deflacionados.

Durante um período de apenas três anos houve um aumento considerável de 527,84\% dos gastos com a subfunção "transferências de Convênio-Educação" no estado do Pará e um aumento 
na participação percentual desse tipo de alocação do recurso também significativo. No que se refere às despesas com "transferências de recursos orçamentários a instituições privadas sem fins lucrativos por categoria econômica", os dados da Tabela 13 merecem atenção:

Tabela 13: Despesas liquidadas com transferências de recursos orçamentários a instituições privadas sem fins lucrativos por categoria econômica - Pará - 2013 a 2018

\begin{tabular}{|c|c|c|c|}
\hline $\begin{array}{c}\text { ANO } \\
\mathbf{2 0 1 3 / 2 0 1 8}\end{array}$ & $\begin{array}{c}\text { OUTRAS DESPESAS } \\
\text { CORRENTES }\end{array}$ & $\begin{array}{c}\text { DESPESAS DE } \\
\text { CAPITAL }\end{array}$ & Total \\
\hline 2013 & $710.746,22$ & 0,00 & $710.746,22$ \\
\hline 2014 & $2.175 .201,78$ & $408.404,17$ & $2.583 .605,95$ \\
\hline 2015 & $2.302 .537,43$ & 0,00 & $2.302 .537,43$ \\
\hline 2016 & $33.601,64$ & $218.297,17$ & $251.898,82$ \\
\hline 2017 & $268.330,06$ & 0,00 & $268.330,06$ \\
\hline 2018 & $329.080,66$ & $4.149,82$ & $333.230,48$ \\
\hline
\end{tabular}

Fonte: SIOPE-FNDE - Relatório de dados informados pelas UFs - Consolidado de despesa PA. Dados deflacionados.

Os gastos com Transferências de recursos para instituições privadas sem fins lucrativos compreendem as "[...] despesas orçamentárias realizadas mediante transferência de recursos financeiros a entidades sem fins lucrativos que não tenham vínculo com a administração pública" (BRASIL, MPOG, 2017, p. 61). Foram obtidos a partir da análise dos "relatórios de dados informados pelas UFs" ao SIOPE, levando em conta as despesas orçamentárias realizadas no âmbito da modalidade de aplicação " 50 - transferências a instituições privadas sem fins lucrativos" e, segundo Salvador (2017), as duas principais estruturas jurídicas presentes na legislação brasileira que podem receber recursos públicos como instituições privadas sem fins lucrativos são as Organizações Sociais (OS) e as Organizações da Sociedade Civil de Interesse Público (OSCIP).

Conforme já observado por Salvador (2017), em pesquisa publicada no ano de 2017, e a partir dos dados apresentados na Tabela 18, observa-se que o setor privado vem tendo acesso ao fundo público no estado do Pará por meio das transferências de recursos para instituições privadas sem fins lucrativos. Este acesso ao fundo público vinha apresentando tendência de crescimento contínuo até 2015; tem queda brusca em 2016; e volta a apresentar tendência de crescimento, mas em patamares bem menores, nos anos de 2017 e 2018. Assim como no caso das matrículas, novamente os indícios do crescimento constante do setor privado no uso do fundo público se revelam.

\section{CONSIDERAÇÕES FINAIS}

Esta pesquisa, conforme já anunciado ao longo deste artigo, teve por objetivo analisar o papel do Estado, a lógica de financiamento proposta pelas novas regulamentações voltadas para a educação básica e seu efeito determinante / indutor no processo de mercantilização / privatização da educação pública paraense, no período de 2013 a 2018. Para tanto, realizou revisão bibliográfica acerca da temática, mapeou os dispositivos legais nacionais e paraense voltados para a educação básica e que, nos textos, apresentavam indicação de parceria público-privado ou estímulos de acesso pelo setor privado ao fundo público; analisou os dados de oferta - matrícula e estabelecimentos de ensino - à educação básica por dependência de ensino, com foco voltado para a descrição do comportamento e tendências da rede pública e privada; e investigou os gastos com a educação por função e subfunção, identificando as transferências de recursos do orçamento do estado para as entidades privadas. Por meio da análise de cada um desses tipos de dados, foi possível 
perceber tendências de encolhimento do setor público e avanços do setor privado, não apenas na oferta da educação básica, mas também no acesso ao fundo público.

Nesse sentido, o Estado brasileiro/paraense desempenhou um papel importante, viabilizando medidas legais (em âmbito nacional e estadual) que permitiram um avanço "silencioso" do processo de mercantilização / privatização da educação básica; a destinação de recursos financeiros públicos para a iniciativa privada; e o estabelecimento das parcerias público-privadas no estado do Pará, tal como já apontado por outros estudos recentes (SALVADOR, 2017; ADRIÃO, 2018).

Ao longo do período analisado, em relação aos dados de oferta - matrícula e estabelecimentos — no estado do Pará, foi possível perceber as seguintes tendências:

- queda das matrículas totais e do número total de estabelecimentos da educação básica;

- crescimento das matrículas e de estabelecimentos de educação básica na rede federal e privada de ensino - com destaque para a rede privada de ensino que, no atual cenário político-econômico do Brasil, tende a continuar crescendo, enquanto a rede federal de ensino tende a diminuir;

- queda de matrículas e estabelecimentos de educação básica das redes estadual e municipal de ensino;

- crescimento da rede privada de ensino no atendimento a creche, ao ensino fundamental EJA e à educação profissional;

- crescimento da rede privada (conveniada) no atendimento à creche e à pré-escola;

- crescimento da rede privada (não conveniada sem fins lucrativos) no atendimento à creche, à pré-escola, ao ensino fundamental, ao ensino médio, à EJA e à educação profissional;

- crescimento da rede privada (não conveniada com fins lucrativos) no atendimento à creche, ao ensino fundamental, ao ensino médio, à EJA e à educação profissional;

- por outro lado, as redes estadual e municipal de ensino registraram crescimento apenas no atendimento ao ensino médio $(1,43 \%)$ e no atendimento às creches $(75,53 \%)$ respectivamente.

No período em estudo, a análise dos gastos orçamentários, mais especificamente dos gastos por função, revelou que a prioridade política do estado do Pará, tem sido com os gastos com encargos especiais, ou seja, com pagamentos do refinanciamento da dívida interna e externa. Em que pesem os gastos com a função educação terem aumentado ao longo do período estudado, esse aumento não se fez refletir em nenhuma das etapas de ensino da educação básica, que caiu -11,27\% e teve sua participação, em relação aos gastos totais da função, reduzida de 68,85\% em 2013 para $55,32 \%$ em 2018.

O acesso ao fundo público pelo setor privado no estado do Pará é expresso por meio dos dados de transferências de Convênio-Educação e por meio das transferências de recursos para instituições privadas sem fins lucrativos. O primeiro, durante um período de apenas três anos (2016 a 2018), registrou aumento considerável de $527,84 \%$ nos gastos. No que se refere às transferências de recursos para instituições privadas sem fins lucrativos, estas vinham apresentando tendência de crescimento contínuo até 2015; caem bruscamente em 2016; e voltam a apresentar tendência de crescimento, em patamares bem menores, nos anos de 2017 e 2018. O mapeamento da situação paraense permite afirmar a pertinência da preocupação com o "fantasma" da privatização que ultrapassa o nível da ameaça e vai se instalando no orçamento e na estrutura da oferta educacional. 


\section{REFERÊNCIAS}

ADRIÃO, Theresa. Dimensões e formas da privatização da educação no Brasil: caracterização a partir de mapeamento de produções nacionais e internacionais. In: Currículo sem Fronteiras, v. 18, n. 1, p. 8-28, jan./abr. 2018.

BRASIL. Ministério do Planejamento, Desenvolvimento e Gestão. Secretaria de Orçamento Federal. Manual Técnico de Orçamento - MTO. Edição 2018. Brasília, 2017.

CARVALHO, Elma Júlia Gonçalves de. A educação básica brasileira e as novas relações entre o Estado e os empresários. In: Retratos da Escola, Brasília, v. 11, n. 21, p. 525-541, jul./dez. 2017.

CNTE. Dossiê: Privatização da e na educação: projetos societários em disputa. Retratos da Escola / Escola de Formação da Confederação Nacional dos Trabalhadores em Educação (Esforce). Brasília, v. 11, n. 21, jul./dez. 2017.

GARCIA, Teise. Dossiê: Dimensões de privatização na educação básica: diferentes contextos em análise. In: RPGE - Revista online de Política e Gestão Educacional. Araraquara, v. 22, n. esp. 3, p. 12361240, dez. 2018.

INEP. Resumo Técnico: Censo da Educação Básica 2018 [recurso eletrônico]. Brasília: Instituto Nacional de Estudos e Pesquisas Educacionais Anísio Teixeira, 2019.

MORI, Andrey; ADRIÃO, Theresa. Estado do conhecimento sobre financiamento da educação obrigatória e a privatização a partir da Web of Science, 2015-2018. In: RPGE - Revista online de Política e Gestão Educacional. Araraquara, v. 22, n. esp. 3, p. 1241-1257, dez. 2018.

NUNES, Alynne Nayara Ferreira. Financiamento da educação básica no Brasil: uma análise dos arranjos jurídicos adotados ao longo do período republicano In: Revista Digital de Direito Administrativo, v. 4, n. 1, p. 32-58, 2017.

OLIVEIRA, Ney Cristina Monteiro. A relação público privada na educação básica brasileira: as implicações do neogerencialismo como modelo de gestão. In: Margens - Revista Interdisciplinar. Dossiê: Trabalho e Educação Básica Versão Digital. v. 11, n. 16, p. 57-67, jun. 2017.

PARÁ. Secretaria de Estado da Fazenda. Balanço Geral do Estado 2013. Belém: SEFA, 2014.

PARÁ. Secretaria de Estado da Fazenda. Balanço Geral do Estado 2014. Belém: SEFA, 2015.

PARÁ. Secretaria de Estado da Fazenda. Balanço Geral do Estado 2015. Belém: SEFA, 2016.

PARÁ. Secretaria de Estado da Fazenda. Balanço Geral do Estado 2016. Belém: SEFA, 2017.

PARÁ. Secretaria de Estado da Fazenda. Balanço Geral do Estado 2017. Belém: SEFA, 2018.

PARÁ. Secretaria de Estado da Fazenda. Balanço Geral do Estado 2018. Belém: SEFA, 2019.

PERONI, Vera; CAETANO, Maria Raquel; LIMA, Paula de. Reformas educacionais de hoje: as implicações para a democracia. In: Retratos da Escola. Brasília, v. 11, n. 21, p. 415-432, jul./dez. 2017. PERONI, Vera e SHEIBE, Leda. Privatização da e na educação: projetos societários em disputa. In: Retratos da Escola. Brasília, v. 11, n. 21, p. 387-392, jul./dez. 2017.

PIOLLI, Evaldo. O processo de mercantilização da educação e o novo ciclo de reformas educacionais no Brasil pós-golpe institucional de 2016. In: Revista Exitus. Santarém/Pará, v. 9, n. 1, p. 17-33, jan./mar. 2019.

POLANYI, Karl. A grande transformação: as origens de nossa época. Tradução de Fanny Wrabel. 2. ed. Rio de Janeiro: Compus, 2000.

RIKOWSKI, Glenn. Privatização em educação e formas de mercadoria. In: Retratos da Escola. Brasília, v. 11, n. 21, p. 393-413, jul./dez. 2017. 
SALVADOR, Evilásio. Privatização e mercantilização da educação básica no Brasil. Brasília, DF: Universidade de Brasília: Confederação Nacional dos Trabalhadores em Educação, 2017.

SANTOS, Sayarah Carol Mesquita dos. Políticas de privatização da educação básica no Brasil: alguns apontamentos. Pesquisa em Foco. São Luís, v. 22, n. 1, p. 248-261, jan./jun. 2017.

SANTOS, Terezinha Fátima Andrade Monteiro. Programas de melhoria da educação básica e profissional no Pará via parcerias público-privadas. Projeto de pesquisa desenvolvido no Instituto de Ciências da Educação da Universidade Federal do Pará. Belém, UFPA, 2014.

SAVIANI, Dermeval. Da Nova LDB ao FUNDEB: por uma outra política educacional. Campinas: Autores Associados, 2007.

VALE, Cassio. Setor Privado no Ensino Médio Paraense: Contribuições? In: VIII Jornada Internacional de Políticas Públicas. São Luís, Maranhão, 22 a 25 ago. 2017. Disponível em: http://www.joinpp.ufma.br/jornadas/joinpp2017/pdfs/eixo3/setorprivadonoensinomedioparae nsecontribuicoes.pdf. Acesso em: 2 abr. 2019.

VALE, Cassio. Subsunção do público ao privado na educação paraense. Dissertação (Mestrado em Educação) - Universidade Federal do Pará, Instituto de Ciências da Educação, Programa de PósGraduação em Educação, Belém, 2017.

VIZZOTTO, Liane; CORCETTI, Berenice; PIEROZAN, Sandra. O público e o privado para os serviços sociais. In: Retratos da Escola. Brasília, v. 11, n. 21, p. 543-556, jul./dez. 2017.

Submetido em março de 2020. Aprovado em abril de 2020.

\section{Informações do(a) autor(a)}

Fabrício Aarão Freire Carvalho

Programa de Pós-Graduação em Currículo e Gestão da Escola Básica (PPEB/NEB/UFPA)

E-mail: fafc33@gmail.com

ORCID: https://orcid.org/0000-0002-4753-2560

Link Lattes: http://lattes.cnpq.br/6240386868511581

Andréa Barbosa Gouveia

Universidade Federal do Paraná (UFPR)

E-mail: andreabg@ufpr.br

ORCID: https://orcid.org/0000-0002-8260-2720

Link Lattes: http://lattes.cnpq.br/5282311026967237 